\title{
Use of 3D Scanning Technologies to Extract Body Measurements for Customised Size Charts for Predominant African and Caucasian Body Shapes in South Africa
}

\author{
Bukisile P. MAKHANYA ${ }^{* 1}$, Helena M. DE KLERK ${ }^{1}$, Amukelani MUTHAMBI ${ }^{1}$, Karien ADAMSKI ${ }^{2}$ \\ ${ }^{1}$ Department Consumer Science, University of Pretoria, South Africa; \\ ${ }^{2}$ Department Statistics, University of Pretoria, South Africa
}

DOI: $10.15221 / 15.243$ http://dx.doi.org/10.15221/15.243

\begin{abstract}
The South African sizing system was adapted from an out-dated British sizing system. This contributes to the fit problems currently experienced by female apparel consumers in South Africa. To improve ready-to-wear apparel fit, body measurements and body shapes prevalent within a target population need to be identified and subsequently form a basis for a sizing system. The South African apparel industry bases apparel design and manufacturing on standard figures yet research shows that female consumer populations consist of women of different body shapes and body proportions. Diverse ethnic groups within populations further aggravate the variations. Differently shaped consumers experience different fit problems from standard apparel and size charts and therefore require differently shaped apparel. In an attempt to address ready-to-wear apparel fit problems among the ethnically diverse South African female population, this paper sought to compile customised size charts of body shape classes predominant among African and Caucasian women. This paper utilised scan data of 233 African $(n 1=109)$ and Caucasian $(n 2=125)$ women aged $18-25$ years that were selected using the purposive and snow-balling techniques. Body shape descriptors from literature guided body shape classification formulae that were computed from circumferential drop values of the samples and mean \pm standard deviation. These were used to classify participants' bodies into different body shape categories. A print-out of virtual body images showing participants' front and side view images were subjected to visual analysis by a panel of experts to confirm body shapes assigned from measurements. The body shape defining parameters adopted in this study were. triangle: Mean to Maximum (in $\mathrm{cm}$ ) i.e. $12.6 \leq$ hip - bust $\leq 29.8$, hourglass: Mean $\leq$ bust - waist $\leq$ Maximum i.e. $18 \leq$ bust - waist $\leq 26.6$ and rectangle: Mean $(18 \mathrm{~cm})-3 \times$ SD $(12.3 \mathrm{~cm})<$ bust - waist < mean i.e. $5.6<$ bust - waist $<18$. Findings show that there were 64 African triangle, 42 Caucasian triangle, 30 African hourglass, 51 Caucasian hourglass, 14 African rectangle and 32 Caucasian rectangle. The significant differences between the Caucasian hourglass figure assumed to be similar to the Western hourglass used as a standard figure by ready-to-wear apparel manufacturing, confirmed need for customised size charts for the predominant body shapes among South African women.
\end{abstract}

This paper resulted in the computation of customised size charts for the different predominant African and Caucasian body shapes. While there are a number of Western studies that classify body shape using drop values, there has not been such study in South Africa.

Key words: African, Caucasian, Ready-to-wear apparel, Apparel fit, 3D body scanning technologies

\section{Introduction}

Ready-to-wear (RTW) apparel is manufactured based on sizing systems [1]. A sizing system is a chart of body dimensions created by dividing the target market into different body shape categories based on similar key dimensions such as height or circumferential ratios [2]. It is a method used to create apparel that would fit a target population of different sizes [3]. Apparel firms identify and base their sizing systems on a standard figure, measurements of which are proportionately graded into sets of bigger and smaller sizes [4]. Grading results in similar shaped apparel as the base pattern and consequently, poor fit for consumers with different body shapes from the ideal figure.

\footnotetext{
* bksImakhanya@gmail.com +268 76125475 (mobile); +268 25170522 (W); +26824040780 (H)
} 
The sizing system used by the South African apparel industry was adapted from an old British sizing [5]. This results in ill-fitting apparel as the base pattern is not only foreign to South Africa, but is also based on out dated and inaccurate anthropometric data. This then necessitated a need for customised size charts of the different shapes. The South African industry like a majority of apparel manufacturers worldwide still does not cater for figure shape variations [5]. In most cases the standard body measurements used in some sizing systems are not representative of the companies' target markets [4], and they vary from one apparel manufacturer to the next [6], which compounds apparel fit problems. Manufacturers therefore need to understand body shape differences within populations and take them into consideration during RTW apparel designing and production in order to give better fitting apparel.

The South African population consist of diverse ethnic groups among which are the African and Caucasian groups, which are of interest in this paper. RTW apparel fit problems are further aggravated if the target population consists of diverse ethnic groups. In many Western countries, variations in female apparel consumers' body shapes are to a large extent attributed to the diverse ethnic groups $[7 ; 8 ; 9]$. Studies $[10 ; 11 ; 12]$ identified the three predominant body shapes among African and Caucasian women in South Africa as triangle, hourglass and rectangle and found a significant association between ethnicity and body shape prevalence. There are five predominant body shapes adopted in this study, these are triangle, inverted triangle, hourglass, rectangle and apple. The body shape assigned is based on the relationship between the bust and/ or shoulders, waist and hip size or circumferences as illustrated by the body shapes and body shape descriptors in fig. 1.

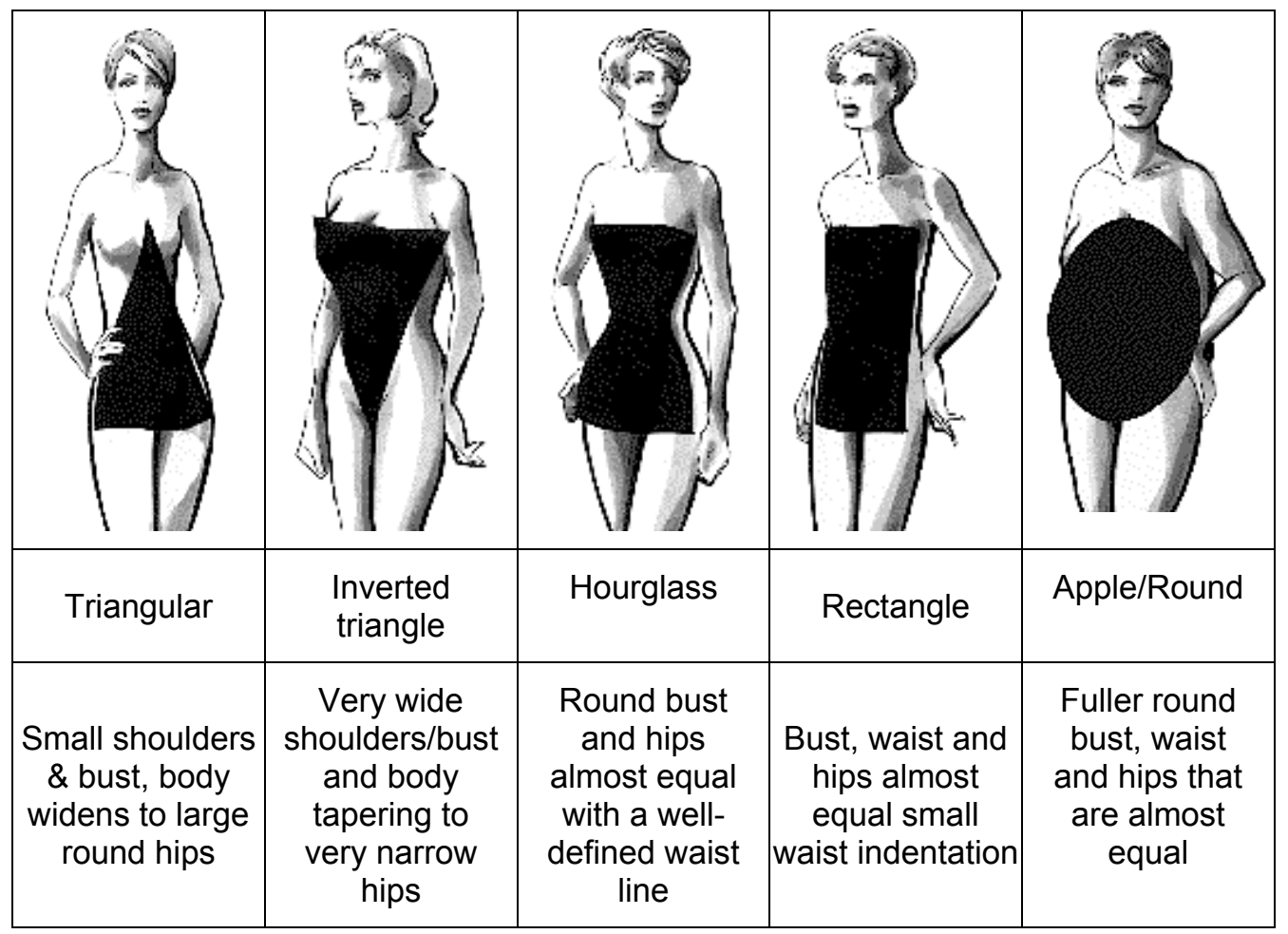

Fig. 1. Female predominant body shapes [13]

Furthermore, $[10 ; 11 ; 12]$ also found significant differences in key body measurements of predominant African and Caucasian body shapes and the Caucasian hourglass that is used by the South African apparel industry as a standard figure. Therefore, the South African apparel industry needs a South African sizing system (size charts) that are representative of most prevalent body shapes among the diverse ethnic groups, which when graded will result in apparel with better fit. Moreover, according to [5], South African manufacturers do not specify the body shapes their apparel is meant to fit as they produce apparel based on standard figures. Until recently, literature suggests that there has not been much research evidence available in South Africa on body shapes prevalent within the different ethnic groups. 
Sizing systems of several countries are based on definitions of figure shapes description of garment sizes, key dimensions used and garment types. Most sizing systems have similarities in the way they classify women's figure shapes, select key dimensions and label garment sizes. Key and secondary dimensions are added to come up with body dimensions used in pattern development [1]. It is suggested that size labels should indicate the body shapes of the individual for whom the garment is made and that size labels should reflect key body measurements for different garment styles [1]. [1] further suggests that key dimensions must always include the absolute value of the largest body measurement in order to be representative of the basic body shape. Some systems use bust circumference for most upper and whole body garments, and the hip and waist circumferences and height for lower body garments. If apparel consumers are to benefit from such apparel size labels, they must know their key body measurements, which is seldom the case. This paper therefore aimed to develop customised size charts for predominant African and Caucasian body shapes in an effort to contribute towards addressing the persistent ill fit experienced by the ethnically diverse South African female consumers from standard RTW apparel.

\section{Literature}

\subsection{Applications of the $3 \mathrm{D}$ body scanning in the clothing industry}

A body scanner is an instrument designed to create a three-dimensionally accurate virtual image of the body, from which measurements are extracted. According to [14], 3 D body scanning provides anthropometric data that can be used for pattern generation to produce customised apparel by transferring body shapes and measurements to Computer-Aided Design (CAD) systems accurately [15]. Three dimensional body scanning technology provides multi-dimensional data that has the potential to provide new insights into sizing and grading systems [14]. The body scanning technology can also be used in size surveys, development of size charts, to scan and to capture and save consumers' virtual images for apparel fit analysis e.g. the internet "virtual try-ons". This enables consumers to try on clothing digitally on their own $3 \mathrm{D}$ body scan images and to also assess apparel fit and style remotely. The "virtual try-ons" contribute towards solving fit problems, and when used for automated fit, they produce better-fitting apparel for the consumer. Three-dimensional scanners also allow for improved customer service in the form of product visualisation and fashion style and size advice when consumers make purchases [16].

Additionally, through the 3D body scanning technology, in developed countries, consumers may have their scan information stored in smart-cards that could be used in in-store kiosks to match a catalogue of ready-made styles with the consumer's exact body shape selection of suitable apparel styles that give them a similar fit as custom-made apparel [17]. It also contributes towards addressing apparel fit challenges that are not adequately addressed by the traditional methods of body measurement. $3 \mathrm{D}$ body scanning can also be used in the communication of sizing and fit in the apparel industry [16]. However, it should be noted that this technology is not readily available in the Southern African region due to the prohibitively high costs. Even though a number of $3 \mathrm{D}$ body scanning applications are widely used in developed countries. The use of the $[T C]^{2}$ NX-12 3 D body scanner was limited to capturing $3 \mathrm{D}$ virtual images and extraction of body measurements of young African and Caucasian women. In addition, the $[\mathrm{TC}]^{2} \mathrm{NX}-16$ Version 5 Software was used to access and manipulate the saved scanned data.

\section{Methodology}

There are about 26.6 million females in South Africa, they comprise of: $79.3 \%$ African, $9 \%$ Coloured, $8.9 \%$ Caucasian, $2.4 \%$ Indian, and $0.4 \%$ other, dispersed throughout the 9 Provinces [18]. The African and Caucasian groups are the two main population groups in the Tshwane, formerly Gauteng Province [18] where this study was conducted. This study is an exploratory research design. The units of analysis were young female apparel consumers of African and Caucasian ethnic origin, aged between 18 and 25 years. These were mainly students from two large Universities (University of Pretoria and Tshwane University of Technology) in Tshwane, a major metropolitan city in South Africa. Scan data of a total sample of 234 participants was obtained (109 African and 125 Caucasian women) was selected using the purposive and snowballing techniques in research [10; 11] that compiled extracts of preliminary findings of a doctoral thesis that was finalised in July 2015 [12]. For purposes of this paper methodologies used in the above research will be summarised. 


\subsection{Scanning process}

Participants wore grey stretchy two-piece scanning garments made of $95 \%$ cotton and $5 \%$ Lycra fabric over their everyday well-fitting undergarments. They then entered the private scanning cubicle. A thick black felt curtain was drawn and sealed with Velcro and weighted hems to prevent light from passing into the scanning cubicle. According to [19], light interferes with the quality of the scan image. The whole body image was captured in approximately 6 seconds and body measurements extracted in about 3 seconds. The unit stopped briefly five to six times to ensure accurate body scanning, bringing the total scan duration to an estimated 54 seconds [19]. Subjects were scanned two times in the normal scanning position with short breaks in between scans, to enable the researcher to assess the quality of scan images before saving them. The bust, waist and hip circumferences were extracted based on the $[\mathrm{TC}]^{2}$ landmarks location outlined in Table 1 . These landmarks are automatically located by the scanner and they indicate where and how each measurement was taken by the $[\mathrm{TC}]^{2} \mathrm{NX}-123$ $\mathrm{D}$ body scanner Version 7.2. The 3 key body measurements used in this study were defined using the Measurements Extraction Profile (MEP) $[T C]^{2}$ NX-16 Version 5 software programme.

Table1. Automatically extracted key body measurements, locating landmarks and location on the body [20; 21; 22]

\begin{tabular}{|c|c|c|c|}
\hline & $\begin{array}{c}\text { BODY } \\
\text { DIMENSIONS }\end{array}$ & {$[T C]^{2}$ LOCATION LANDMARKS } & BODY MEASUREMENT DESCRIPTION \\
\hline \multirow{3}{*}{ 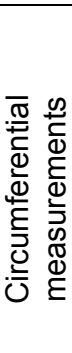 } & $\begin{array}{c}\text { Bust Full/ } \\
\text { Circumference }\end{array}$ & $\begin{array}{l}\text { Vertebral column, lowest part of soft } \\
\text { tissue forming the axilla nipples }\end{array}$ & $\begin{array}{l}\text { Bust girth, maximum circumference measured } \\
\text { under the shoulder blades, under the armpits } \\
\text { across the bust points }\end{array}$ \\
\hline & $\begin{array}{c}\text { Waist Full/ } \\
\text { Circumference }\end{array}$ & $\begin{array}{l}\text { Vertebral column, small of the back, } 4 \mathrm{~cm} \\
\text { above small of the back, waist level }\end{array}$ & $\begin{array}{l}\text { Waist girth, smallest circumference between smal } \\
\text { of back and a level } 4 \mathrm{~cm} \text { above small of back }\end{array}$ \\
\hline & $\begin{array}{c}\text { Hips Full/ } \\
\text { Circumference }\end{array}$ & $\begin{array}{l}\text { Vertebral column, small of back, } \\
\text { prominence of buttocks, crotch }\end{array}$ & $\begin{array}{l}\text { Hip girth, circumference of the fullest side to side } \\
\text { measurement between waist and crotch }\end{array}$ \\
\hline
\end{tabular}

\subsection{Body shape classification}

This paper aimed at compiling customised size charts for the predominant African and Caucasian body shapes identified by $[10 ; 11 ; 12]$. Again for purposes of this paper the body shape classification formulae used in these studies are presented in summary. The body shapes of the two ethnic groups were classified using the relationship between key circumferential measurements, i.e. drop values. Drop values are one method of body shape classification used in a number of studies $[6 ; 7 ; 8]$ that are adapted in this study by incorporating body measurements of the sample. Table 2 shows defining formulae of the different body shapes, the drop values used, and body shape distribution among African and Caucasian women.

Table 2: Body shape classification formulae and distribution of African and Caucasian body shapes

\begin{tabular}{|c|c|c|c|c|}
\hline Body shapes & Drop Values & Defining formulae & $\begin{array}{l}\text { African } \\
\mathrm{n}(\%)\end{array}$ & $\begin{array}{c}\text { Caucasian } \\
\mathrm{n}(\%)\end{array}$ \\
\hline Triangle & \multirow[t]{2}{*}{ Hip - Bust } & $\begin{array}{c}\text { Mean } \leq \text { bust }- \text { waist } \leq \text { Max. } \\
12.6 \leq \text { hip }- \text { bust } \leq 29.8\end{array}$ & $64(58.7)$ & $42(33.6)$ \\
\hline Inverted triangle & & Hip - Bust $<0$ & - & - \\
\hline Hourglass & \multirow[t]{3}{*}{ Bust -Waist } & $\begin{array}{l}\text { Mean } \leq \text { bust }- \text { waist } \leq \text { Max. } \\
18 \leq \text { bust }- \text { waist } \leq 26.6\end{array}$ & $30(27.5)$ & $51(40.8)$ \\
\hline Rectangular & & $\begin{array}{c}\text { Mean }(18)-3 x S D(12.3)<\text { bust }- \text { waist }<\text { mean } \\
5.6<\text { bust }- \text { waist }<18\end{array}$ & $14(12.8)$ & $32(25.6)$ \\
\hline Apple & & $-3.7 \leq$ bust - waist $\leq 5.6$ & $1(0.9)$ & - \\
\hline \multicolumn{3}{|r|}{ Total } & 109 & 125 \\
\hline
\end{tabular}

Measurements in cm. $[10 ; 11 ; 12]$. 


\subsection{Transformation of anthropometric data into size specification}

As mentioned earlier, this paper is a follow-up to two studies $[10 ; 11 ; 12]$ which recommended customised size charts for manufacturing RTW apparel. This paper adopted body shapes already classified in studies by [10; 11; 12]. The methodology modified from [23] utilised three steps, namely: selection of the key dimensions, determining the size range, and the calculation of the body dimensions for the different sizes using least-squares regression analysis. Least-squares regression analysis, in terms of apparel sizing, may be described as a statistical technique in which the values of secondary body dimensions are predicted from known values of the key body dimensions [24]. In least-squares regression analysis, as applied to apparel sizing, the key dimension (i.e. bust) may be considered as the independent variable as it explains the change that occurs in the dependent variables (i.e. waist and hips) [25]. To determine the measurements range for each apparel size of each of the predominant body shapes, for example, for the bust circumference where the grade value is $4 \mathrm{~cm}, 2 \mathrm{~cm}$ were added for the upper limit and $2 \mathrm{~cm}$ were subtracted for the lower limit. The same method was used to come up with the measurement range for the waist and hip circumferences using half of their respective grade values per body shape and apparel size.

With the bust circumference used as the independent variable, estimated regression equations for the waist and the hips were then calculated. A regression equation, in terms of apparel sizing, shows how the bust is related to the waist and the hips, and may be used to predict values of the waist and hips for any given value of the bust [26]. The least-squares regression equation is given as (equation 1):

$$
\hat{y}=b_{0}+b_{1} x
$$

The $\hat{y}$ is the mean value for a known or estimated value of the independent variable $x, b_{0}$ is the $y-$ intercept of the regression line and $b_{1}$ is the slope of the regression line. The Slopes $\left(b_{1}\right)$ and intercepts $\left(b_{0}\right)$ were computed in Microsoft Excel for the prevalent body shapes classified in [10; 11; 12]. The slope, as applied to apparel sizing, represents the estimated rate of change for the waist and hips for every 1 centimetre change in the bust [26]. The intercept remains constant for any given straight line and represents the value of the waist and hips when the bust has a value of $0 \mathrm{~cm}$ [26]. In a study by [27], $85.9 \%$ of the subjects (aged between 18 and 25 years) fell into the size $6 / 30$ to size $14 / 38$ size range. In line with those findings [27], the size $6 / 30$ to $14 / 38$ was also adopted for this study's size specifications.

\section{Results and Discussion}

In the previous studies [6; 7;8], the Kruskal-Wallis test conducted to determine significant differences in selected measurements of the paired body shapes with the Caucasian hourglass were significantly different at a $5 \%$ level of significance. African and Caucasian triangle shapes had significantly smaller bust than Caucasian hourglass both with $p$-values of 0.0000 . Caucasian rectangle had significantly larger waist with a mean difference of $5.7 \mathrm{~cm}$ at $p=0.0026$ and African triangle recorded significantly larger hips at $p=0.000$. These findings confirm literature records that triangle shapes have smaller bust and larger hips than average and rectangle shapes have larger waist than average which prove the need for customised size charts especially at the bust for the African and Caucasian triangle, at the hips for African triangle and at the waist for Caucasian rectangle. Figure 2 shows the front and back view of the African and Caucasian triangle, hourglass and rectangle. It is evident from the images (fig. 2) that the Predominant African and Caucasian body shapes have different characteristics some of which also recorded significantly different body measurements from the Caucasian hourglass that is used by the RTW apparel industry as a standard figure. It should be noted that even though most of the body measurements were not significantly different from those of Caucasian hourglass, they may influence the body shape and subsequently impact apparel fit. 


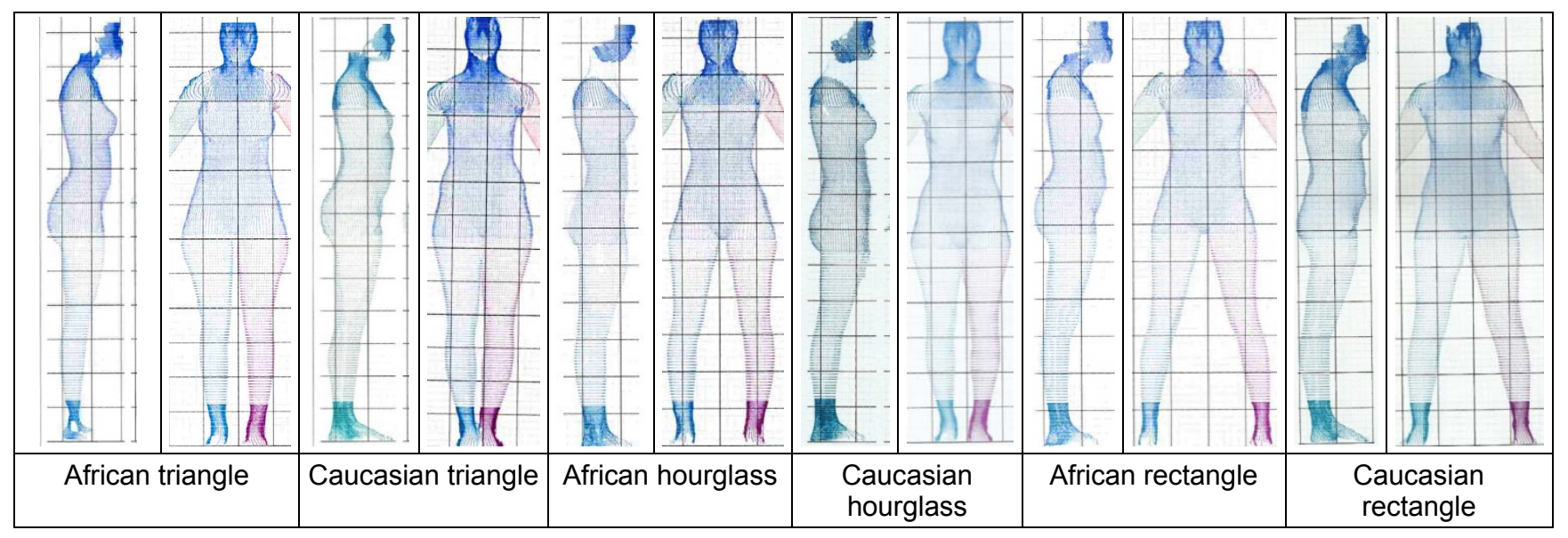

Fig. 2. A front and side view comparison of predominant African and Caucasian body shapes $[10 ; 11 ; 12]$.

The aim of the study was to develop size charts for predominant African and Caucasian body shapes. Following the statistical analysis, values of key dimensions, grade between sizes and slope of different sizes for predominant African and Caucasian body shapes are presented in Table 3. Sizes are ranging from $6 / 30$ to $14 / 38$. It must be noted that Table 3 presents means of key body measurements of consumers of different ethnicity, body shape and apparel size and not apparel measurements. Therefore, since apparel sizes vary by manufacturer and apparel style, ease allowance may be added to these measurements accordingly.

\begin{tabular}{|c|c|c|c|c|c|c|c|c|}
\hline \multicolumn{2}{|c|}{ Size range: } & \multicolumn{7}{|c|}{$6 / 30-14 / 38$} \\
\hline \multicolumn{2}{|c|}{ Age group: } & \multicolumn{7}{|c|}{$18-25$} \\
\hline \multicolumn{2}{|c|}{ Height group: } & \multicolumn{7}{|c|}{ Medium height } \\
\hline \multicolumn{2}{|c|}{ Body shapes: } & \multicolumn{7}{|c|}{ Triangle, hourglass and Rectangle } \\
\hline \multicolumn{2}{|c|}{ Population groups: } & \multicolumn{7}{|c|}{ African and Caucasian } \\
\hline $\begin{array}{l}\text { Body } \\
\text { shape }\end{array}$ & $\begin{array}{c}\text { Key } \\
\text { circumferential } \\
\text { measurements }\end{array}$ & $\begin{array}{l}\text { Size } \\
6 / 30 \\
\end{array}$ & $\begin{array}{l}\text { Size } \\
8 / 32\end{array}$ & $\begin{array}{c}\text { Size } \\
10 / 34\end{array}$ & $\begin{array}{c}\text { Size } \\
12 / 36\end{array}$ & $\begin{array}{c}\text { Size } \\
14 / 38 \\
\end{array}$ & Grade & Slope \\
\hline \multirow{3}{*}{$\begin{array}{l}\text { African } \\
\text { triangle }\end{array}$} & Bust & 81.00 & 85.00 & 89.00 & 93.00 & 97.00 & 4.00 & - \\
\hline & Waist & 64.33 & 68.02 & 71.71 & 75.41 & 79.10 & 3.69 & 0.92 \\
\hline & Hips & 98.80 & 103.13 & 107.39 & 111.64 & 115.9 & 4.25 & 1.06 \\
\hline \multirow{3}{*}{$\begin{array}{c}\text { Caucasian } \\
\text { triangle }\end{array}$} & Bust & 81.00 & 85.00 & 89.00 & 93.00 & 97.00 & 4.00 & - \\
\hline & Waist & 65.04 & 68.20 & 71.36 & 74.52 & 77.67 & 3.16 & 0.79 \\
\hline & Hips & 97.46 & 101.34 & 105.22 & 109.09 & 112.97 & 3.88 & 0.97 \\
\hline \multirow{3}{*}{$\begin{array}{c}\text { African } \\
\text { hourglass }\end{array}$} & Bust & 81.00 & 85.00 & 89.00 & 93.00 & 97.00 & 4.00 & - \\
\hline & Waist & 61.13 & 64.49 & 67.86 & 71.23 & 74.59 & 3.37 & 0.84 \\
\hline & Hips & 90.57 & 94.11 & 97.66 & 101.20 & 104.75 & 3.55 & 0.89 \\
\hline \multirow{3}{*}{$\begin{array}{c}\text { Caucasian } \\
\text { hourglass }\end{array}$} & Bust & 81.00 & 85.00 & 89.00 & 93.00 & 97.00 & 4.00 & - \\
\hline & Waist & 61.72 & 64.99 & 68.26 & 71.53 & 74.80 & 3.27 & 0.82 \\
\hline & Hips & 90.92 & 94.08 & 97.24 & 100.41 & 103.57 & 3.16 & 0.79 \\
\hline \multirow{3}{*}{$\begin{array}{l}\text { African } \\
\text { rectangle }\end{array}$} & Bust & 81.00 & 85.00 & 89.00 & 93.00 & 97.00 & 4.00 & - \\
\hline & Waist & 64.12 & 68.46 & 72.8 & 77.14 & 81.48 & 4.34 & 1.09 \\
\hline & Hips & 92.19 & 95.49 & 98.79 & 102.09 & 105.39 & 3.30 & 0.82 \\
\hline \multirow{3}{*}{$\begin{array}{l}\text { Caucasian } \\
\text { rectangle }\end{array}$} & Bust & 81.00 & 85.00 & 89.00 & 93.00 & 97.00 & 4.00 & - \\
\hline & Waist & 66.05 & 70.49 & 74.92 & 79.36 & 83.80 & 4.44 & 1.11 \\
\hline & Hips & 92.19 & 95.70 & 99.21 & 102.72 & 106.23 & 3.51 & 0.88 \\
\hline
\end{tabular}

The slope represents the unit change in waist or hip for every $1 \mathrm{~cm}$ bust increase. All body measurements are in $\mathrm{cm}$ and are body dimensions not apparel dimensions. Bust is an independent variable.

Table 3. Size specification for predominant African and Caucasian body shapes. 
Below is the measurement range for each body shape per apparel size (Table 4).

\begin{tabular}{|c|c|c|c|c|c|c|c|}
\hline \multicolumn{2}{|c|}{ Size range: } & \multicolumn{6}{|c|}{$6 / 30-14 / 38$} \\
\hline \multicolumn{2}{|c|}{ Age group: } & \multicolumn{6}{|c|}{$18-25$} \\
\hline \multicolumn{2}{|c|}{ Height group: } & \multicolumn{6}{|c|}{ Medium height } \\
\hline \multicolumn{2}{|c|}{ Body shapes: } & \multicolumn{6}{|c|}{ Triangle, hourglass and Rectangle } \\
\hline \multicolumn{2}{|c|}{ Population groups: } & \multicolumn{6}{|c|}{ African and Caucasian } \\
\hline $\begin{array}{l}\text { Body } \\
\text { shape }\end{array}$ & \begin{tabular}{|c|} 
Key \\
circumferential \\
measurements
\end{tabular} & $\begin{array}{l}\text { Size } 6 / 30 \\
\text { range }\end{array}$ & $\begin{array}{l}\text { Size } 8 / 32 \\
\text { range }\end{array}$ & $\begin{array}{l}\text { Size } 10 / 34 \\
\text { range }\end{array}$ & $\begin{array}{l}\text { Size } 12 / 36 \\
\text { range }\end{array}$ & $\begin{array}{l}\text { Size } 14 / 38 \\
\text { range }\end{array}$ & Grade \\
\hline \multirow{3}{*}{$\begin{array}{l}\text { African } \\
\text { triangle }\end{array}$} & Bust & $>79.10-83.00$ & $>83.10-87.00$ & $>87.10-89.00$ & $>89.00-93.00$ & $>93.10-97.00$ & 4.00 \\
\hline & Waist & $>62.49-66.18$ & $>66.19-69.88$ & $>69.89-73.56$ & $>73.57-77.26$ & $>77.27-79.10$ & 3.69 \\
\hline & Hips & $>96.68-100.93$ & $>100.94-105.19$ & $>105.20-109.51$ & $>109.52-113.77$ & $>113.78-118.03$ & 4.25 \\
\hline \multirow{3}{*}{$\begin{array}{c}\text { Caucasian } \\
\text { triangle }\end{array}$} & Bust & $>79.10-83.00$ & $>83.10-87.00$ & $>87.10-89.00$ & $>89.00-93.00$ & $>93.10-97.00$ & 4.00 \\
\hline & Waist & $>63.47-66.62$ & $>66.6369 .78$ & $>69.79-72.94$ & $>72.95-76.1$ & $>76.11-79.69$ & 3.16 \\
\hline & Hips & $>95.53-99.40$ & $>99.41-103.28$ & $>103.29-107.16$ & $107.17-111.03$ & $>111.04-114.91$ & 3.88 \\
\hline \multirow{3}{*}{$\begin{array}{c}\text { African } \\
\text { hourglass }\end{array}$} & Bust & $>79.10-83.00$ & $>83.10-87.00$ & $>87.10-89.00$ & $>89.00-93.00$ & $>93.10-97.00$ & 4.00 \\
\hline & Waist & $>59.45-62.82$ & $>62.83-66.19$ & $>66.20-69.55$ & $>69.56-72.91$ & $>72.92-76.28$ & 3.37 \\
\hline & Hips & $>88.80-92.35$ & $>88.81-95.89$ & $>95.90-99.44$ & $>99.45-102.98$ & $>102.99-106.53$ & 3.55 \\
\hline \multirow{3}{*}{$\begin{array}{l}\text { Caucasian } \\
\text { hourglass }\end{array}$} & Bust & $>79.10-83.00$ & $>83.10-87.00$ & $>87.10-89.00$ & $>89.00-93.00$ & $>93.10-97.00$ & 4.00 \\
\hline & Waist & $>60.37-63.63$ & $>63.64-65.28$ & $>65.29-69.90$ & $>69.91-73.17$ & $>73.18-76.44$ & 3.27 \\
\hline & Hips & $>89.34-92.50$ & $>92.51-95.67$ & $>95.68-98.82$ & $>98.83-101.99$ & $>102.00-105.15$ & 3.16 \\
\hline \multirow{3}{*}{$\begin{array}{c}\text { African } \\
\text { rectangle }\end{array}$} & Bust & $>79.10-83.00$ & $>83.10-87.00$ & $>87.10-89.00$ & $>89.00-93.00$ & $>93.10-97.00$ & 4.00 \\
\hline & Waist & $>61.95-66.29$ & $>66.30-70.63$ & $>70.64-74.97$ & $>74.98-79.31$ & $>79.32-83.65$ & 4.34 \\
\hline & Hips & $>90.54-93.84$ & $>93.85-97.14$ & $>97.15-100.44$ & $>100.45-103.74$ & $>103.75-107.04$ & 3.30 \\
\hline \multirow{3}{*}{$\begin{array}{c}\text { Caucasian } \\
\text { rectangle }\end{array}$} & Bust & $>79.10-83.00$ & $>83.10-87.00$ & $>87.10-89.00$ & $>89.00-93.00$ & $>93.10-97.00$ & 4.00 \\
\hline & Waist & $>63.83-68.27$ & $>68.28-72.71$ & $>72.72-77.14$ & $>77.15-81.58 .36$ & $>81.58-86.02$ & 4.44 \\
\hline & Hips & $>90.44-93.94$ & $>93.95-97.46$ & $>97.47-100.97$ & $>100.98-104.48$ & $>104.48-107.99$ & 3.51 \\
\hline
\end{tabular}

All body measurements in $\mathrm{cm}$ measurements. Bust is an independent variable.

Table 4. Measurement range of the African and Caucasian body shapes per apparel size.

Findings of this paper provide young African and Caucasian RTW apparel consumers of different body shapes with customised size charts, key measurement ranges within each apparel size category. This informs RTW apparel consumers of their bust, waist and hip measurements of different body shape which may assist them during RTW apparel selection. These findings also provide RTW apparel manufacturers with key body measurements as well as measurement ranges per body shape and apparel size of the different body shapes prevalent among African and Caucasian women. However, the size charts computed in this paper is a work in progress as they need study may be tested for fit on women of similar ethnicity and body shapes before they could be adopted.

\section{Conclusion and Recommendations}

In order for the South African apparel industry to give better fit to a majority of the young African and Caucasian women, they should base pattern making and apparel production on body shapes and sizes that are representative of their target markets for example, predominant body shapes among the young African and Caucasian women are the hourglass, triangle and rectangle shapes. Since the measurements and body shape characteristics of similar body shapes differed according to ethnicity, each body shape should have different base patterns for the different ethnic groups. Moreover, it is also evident from the findings that the apparel fit needs of the ethnically diverse South African female consumer population cannot be satisfied by the use of one standard figure. The size specification computed by this paper may contribute towards the formulation of the much anticipated South African sizing system. This may lead to apparel consumer loyalty, repeat purchases and increased revenue for both apparel manufacturers and retailers. However, it should be noted that due to the nonprobability sampling techniques employed and the smaller sample size of young African and Caucasian female apparel consumers, the findings and conclusion drawn from this study cannot be generalised to the entire South African female RTW apparel consumers. It is recommended that the size charts from this paper be tested for fit satisfaction and thereafter they may be utilised by apparel designers and manufacturers. Furthermore, apparel manufacturers targeting the ethnically diverse South African RTW apparel consumers may also benefit from this paper. 


\section{References}

[1] A. Petrova, Creating sizing systems, in Ashdown, S.P. Ed. Sizing in clothing: developing effective sizing systems for ready to wear clothing. New York: Wood Head Publishing Limited, 2007, pp.5766.

[2] D. H. Branson and J. Nam, Materials and sizing, in S. P. Ashdown, Ed. Sizing in clothing: developing effective sizing systems for ready to wear clothing. New York: Wood Head Publishing Limited, 2007, pp. 264.

[3] R. E. Glock and G. I. Kunz, Apparel manufacturing, sewn products analysis. New York: Prentice Hall, 1995, pp.157.

[4] N. A. Schofield, Pattern grading. In S. P. Ashdown, Ed. Sizing in clothing: developing effective sizing systems for ready to wear clothing. New York: Wood Head Publishing Limited, 2007, pp. 152.

[5] M. Strydom and H. M. De Klerk, "The South African clothing industry: problems experienced with body measurements," J. of Family Ecology \& Consumer Studies. vol. 34, p. 80-89, 2006.

[6] S. H. Shin and C. L. Istook, "The importance of understanding the shape of diverse ethnic female consumers for developing jeans sizing systems," Int. J. of Consumer Studies, vol. 31, p.135-143, 2007.

[7] P. Devarajan and K. Istook, "Validation of female figure identification technique (FFIT) for apparel software," J. of Textile and Apparel, Technol. and Manage., vol. 4, no. 1, p.1-23, 2004.

[8] K. Simmons et al., 2004. "Female figure identification technique (FFIT) for apparel. Part 1: describing female shapes," J. of Textile and Apparel, Technol. and Manage, vol. 4, no. 1, p. 1-5, 2004.

[9] Y. M. Lee et al., "Comparison of body shape between USA and Korean women", Int. J. of Cloth. Serv. and Technol., vol.19, no. 5, p. 374-391, 2007.

[10] B. P. Makhanya et al., "Body shape characteristics of African and Caucasian female consumers," in 2013 Int.Textiles and Costume Congr. Proc. "Silk-Aesthetic, Culture, History, Technol., Fashion and Innovation," 2013, pp. 413- 418.

[11] B. P. Makhanya et al., "Ethnicity, body shape differences and female consumers' apparel fit problems," Int. J. of Consumer Studies. vol.38, pp. 183-191, 2014.

[12] B. P. Makhanya, "Body shapes characteristics, body cathexis, apparel fit preferences and problems of African and Caucasian women," Ph.D. dissertation, Dpt., Cons. Sc., Univ. of Pretoria. Pta, July, 2015.

[13] J. Liddelow, (2011). What is your body shape? [Online] Available at: www.style-makeoverhq.com/bodyshapehtml.

[14] E. K. Bye et al., Analysis of body measurement systems for apparel. Clothing and Textiles Res. J. in Int. Textile and Apparel Assoc., vol. 24 no. 2, p. 66-79, 2006.

[15] A. Petrova and S.P. Ashdown, 2008. Three-dimensional body scan data analysis: body size and shape dependence of ease values for pants' fit [Online] Available: http://ctri.sagepub.com hosted at http://online.sagepub.com.

[16] B. Xu, et al., "Three-dimensional body scanning system for apparel mass customization," Society of Photo-Optic. Instru. Engineers, vol. 41, no. 7, p.1475-1479, 2002.

[17] [TC] ${ }^{2}$. (2005). Size USA user group meeting [Online] Available at: http://www.tc2.com/what/sizeusa/index.html\#flh.

[18] Census, 2011 Census in brief - Statistics South Africa. Pretoria: Statistics South Africa, 2012.

[19] J. Lu, \& M. J Wang, "Automated anthropometric data collection using 3D whole body scanners," Expert Syst. with Applicat., vol. 35, p. 407- 414, 2008.

[20] A. Beazley, "Size and fit: procedure in undertaking a survey of body measurements, Part 1," J. of Fashion Market. and Manage., vol. 2, no. 1, p. 55-85, 1996.

[21] J. Bougourd, National sizing survey: data collection specification. London: London College of Fashion, 2004.

[22] W. YU, Subjective assessment of clothing, in J. Fan, W. Yu, \& L. Hunter Eds., Clothing appearance and fit: science and technology, New York: Wood Head, 2004.

[23] M. L. Mpampa et al., "A new methodology for the development of sizing systems for the mass customization of garments," Int. J. of Cloth. Sc. and Technol., Vol. 22, no. 1, p. 49-68, 2010.

[24] A. P. Field, Discovering statistics using SPSS: (and sex and drugs and rock ' $n$ ' roll). 3rd ed. London: Sage Publications, pp. 821, 2009.

[25] D. R. Anderson et al., Modern business statistics with Microsoft Excel. Cincinnati: South Western, pp. 936, 2003.

[26] A. Swanepoel et al., Quantitative statistical techniques. 3rd ed., Pretoria: Van Schaik Publishers, pp.232, 2009.

[27] A. Muthambi," Proposed sizing for young South African women of African descent with triangular shaped bodies," M. Cons Sc. thesis, Dept., Cons. Sc., Univ. of Pretoria, Pta, 2012. 